Research Article

\title{
Research on the Influence of Time-Varying Excitation on Vibration Characteristics of the Spiral Bevel Geared Transmission System with Broken Teeth
}

\author{
Dalian Yang $\left(\mathbb{D},{ }^{1}\right.$ Liman Chen $\mathbb{D}^{1},{ }^{1}$ Lingli Jiang $\mathbb{D}^{2},{ }^{2}$ Ping Wang $\mathbb{D},{ }^{3}$ and Jie Tao ${ }^{1}$ \\ ${ }^{1}$ Hunan Provincial Key Laboratory of Health Maintenance for Mechanical Equipment, \\ Hunan University of Science and Technology, Xiangtan 411201, China \\ ${ }^{2}$ School of Mechanical \& Electrical Engineering, Foshan University, Foshan 528225, China \\ ${ }^{3}$ Hunan Power Machinery Research Institute, Aero Engine Corporation of China, Zhuzhou 412002, China \\ Correspondence should be addressed to Lingli Jiang; linlyjiang@163.com and Ping Wang; wp608@sina.com
}

Received 29 August 2020; Revised 10 December 2020; Accepted 6 January 2021; Published 11 February 2021

Academic Editor: F. Viadero

Copyright (C) 2021 Dalian Yang et al. This is an open access article distributed under the Creative Commons Attribution License, which permits unrestricted use, distribution, and reproduction in any medium, provided the original work is properly cited.

\begin{abstract}
Due to heavy and alternating loads of working conditions, spiral bevel gears are prone to broken tooth failures. To solve the problem of vibration characteristic of spiral bevel geared transmission with broken tooth failures that is unknown, this study, considering time-varying mesh stiffness and friction excitation, proposed a torsional vibration dynamic model of spiral bevel geared transmission, which has more simple transmission path and the smaller signal attenuation. First, the time-varying excitations of various broken tooth failure are calculated and introduced into the torsional vibration dynamic model. The vibration response of spiral bevel geared transmission with various broken tooth failures is analysed in the time-frequency domain. Then, the sensitivity of the time-domain statistical index and the frequency domain components to different broken tooth failures are studied. Finally, the correctness of the simulation is verified by experiment. The results show that the crest factor is sensitive to minor tooth failure (10-30\%), while kurtosis is sensitive to severe failure (30-60\%). With the increase of degrees of broken tooth failure, the energy of the low-frequency band increases obviously.
\end{abstract}

\section{Introduction}

Spiral bevel geared transmission system has been widely used in industrial machinery, automobile, and aviation due to its advantages of high speed, heavy load, and smooth operation. Spiral bevel gears often suffer from alternating loads in the working process and are prone to tooth failure [1-5]. The fracture of gear tooth will change the original time-varying excitation of the transmission system, which will aggravate the vibration of the transmission, reduce the transmission efficiency, and endanger the safety of equipment [6-9]. It is necessary to explore the relationship between the time-varying excitation and response characteristics of the spiral bevel geared transmission system for mechanical state evaluation and health maintenance.
The spiral bevel geared transmission is a time-varying nonlinear system. To study the torsional vibration characteristics of the spiral bevel geared transmission system with broken tooth, the time-varying excitation of the transmission under the failure state should be defined first. Timevarying meshing stiffness, as a major time-varying excitation of the geared transmission system, has become the focus of domestic and foreign scholars [10-12]. For example, Chen et al. [13] simplified the gear tooth into a cantilever beam to study the analytical calculation model of time-varying meshing stiffness and obtain the static meshing stiffness. Wang $[14,15]$ calculated the analytic solutions of timevarying meshing stiffness of spur and helical gears using the slice method and explored the influences of factors such as misalignment, lead crown relief, and axial mesh force on 
time-varying meshing stiffness of gears. Tang and $\mathrm{Pu}$ [16] established the meshing model of spiral bevel gears by using finite element software and then obtained dynamic and more accurate time-varying mesh stiffness. In recent years, the research results found that another important timevarying excitation friction moment has caused the attention of scholars $[17,18]$. So, it is proposed that both time-varying meshing stiffness and time-varying friction moment must be considered in the analysis of transmission [19]. The existing research work is mostly based on cylindrical geared transmission [20-22] and has few research studies on the spiral bevel geared transmission system. In order to study the vibration characteristics of gear transmission, scholars have given a variety of dynamic models [23]. Since the geared transmission mainly transmits torque, torsional vibration more directly reflects the operating state of the system compared with bending vibration, and the torsional vibration transmission path is simple, with less signal attenuation [24]. Therefore, the torsional vibration model is widely used in the fault dynamics analysis of the spiral bevel gear transmission system. For example, Zhang et al. [25] studied the mathematical model of the meshing process and typical gear failures and demonstrated the superiority of the torsional vibration analysis method in failure diagnosis of geared transmission. Yang et al. [26] considered timevarying meshing stiffness and time-varying friction to establish a failure model of spur gear with broken tooth and studied the torsional vibration characteristics of the transmission system. Doan and Karpat [27] established a dynamic model of the spur geared transmission containing the broken tooth failure and identified the broken tooth failure using torsional vibration response. To sum up, scholars have carried out extensive research studies on the vibration characteristics of geared transmission with failures, among which there are few studies about broken tooth failures with time-varying excitation. These research studies that are focused on torsional vibration response of spiral bevel geared transmission are rarely involved.
Aiming at these problems, this study intends to propose a dynamic model of spiral bevel geared transmission that considering time-varying mesh stiffness and friction excitation calculates the time-varying excitation with broken tooth failure and then studies the torsional vibration response characteristics in time and frequency domain. In the end, the correctness of the simulation is verified by experiments, which can provide theoretical reference for the fault diagnosis of the spiral bevel geared transmission system.

\section{Dynamic Model of the Spiral Bevel Geared Transmission System}

2.1. Mathematical Model of the Spiral Bevel Geared Transmission System. The geared transmission system is a continuous model with infinite degrees of freedom. The finite element method is used to simplify the continuous model into a combination of finite elements connected to each other at the nodes, so that the problem becomes a mechanical problem with finite degrees of freedom. Thus, it can be solved by using linear equations. For torsional vibration, the discrete mechanical model of the spiral bevel geared transmission system includes mass element, elastic element, and damping element. The simplified dynamic model of the transmission system is shown in Figure 1.

$I_{e}$ and $I_{g}$ are, respectively, the equivalent moment of inertia of pinion and gear. Suppose the system has $n$ degrees of freedom, its generalized coordinates are $\left\{\theta_{1}, \theta_{2}, \ldots, \theta_{k}, \theta_{k+1}, \ldots, \theta_{n-1}, \theta_{n}\right\}$. The dynamic equation of the transmission system is established by using the finite element method as follows:

$$
\ddot{I}+C \dot{\theta}+K \theta=Q
$$

where $I$ is the rotational inertia matrix, $I=\operatorname{diag}\left[\begin{array}{lllllllll}J_{1} & J_{2} & J_{3} & \cdots & J_{k} & J_{k+1} & \cdots & J_{n-1} & J_{n}\end{array}\right]^{\mathrm{T}}$, and $J$ is the moment of inertia of each microelement. The moment of inertia of pinion and gear are $J_{k}$ and $J_{k+1}$, respectively.

$C$ is the damping matrix:

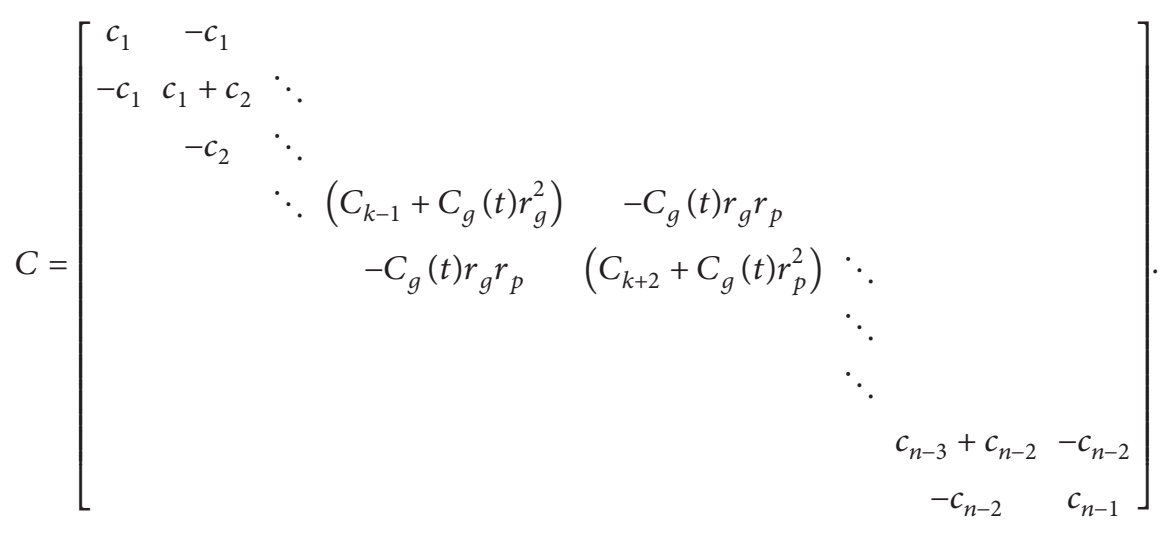




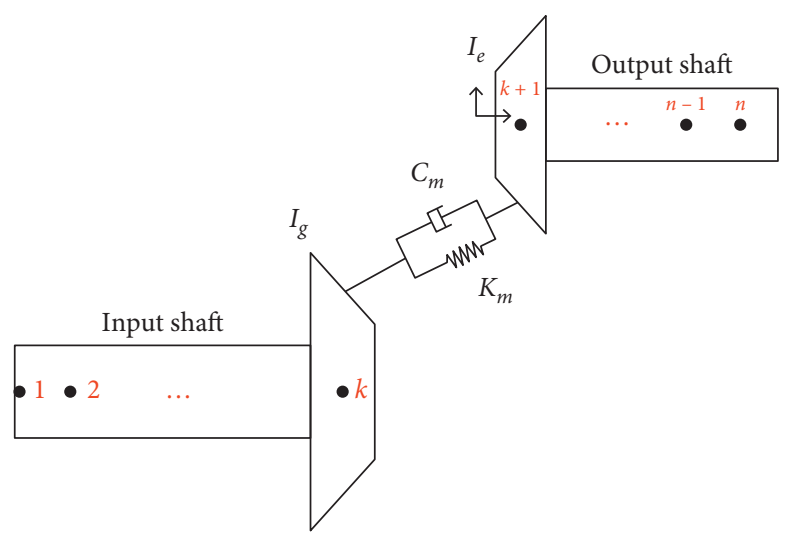

FIGURE 1: Dynamic model of the spiral bevel geared transmission system.

$C_{i}$ is the torsional damping of each element:

$$
C_{i}=2 \zeta\left[\frac{k_{i}}{\left[\left(1 / J_{i}\right)+\left(1 / J_{i+1}\right)\right]}\right]^{1 / 2} .
$$

$C_{g}$ is the meshing damping:

$$
C_{g}=2 \zeta_{m}\left[\frac{K_{g}}{\left[\left(r_{g}^{2} / J_{k}\right)+\left(r_{p}^{2} / J_{k+1}\right)\right]}\right]^{1 / 2},
$$

where $r_{p}$ and $r_{g}$ are the base radius of the main and driven gears, respectively, $\zeta$ is the damping ratio of the axial element, and $\zeta_{m}$ is the mesh damping ratio.

$K$ is the torsional stiffness matrix:

$$
q K=\left[\begin{array}{ccccccc}
k_{1} & -k_{1} & & & & & \\
-k_{1} & k_{1}+k_{2} & \ddots & & & & \\
& -k_{2} & \ddots & & & & \\
& & \ddots & \left(k_{k-1}+K_{g}(t) r_{g}^{2}\right) & -K_{g}(t) r_{g} r_{p} & & \\
& & & -K_{g}(t) r_{g} r_{p} & \left(k_{k+2}+K_{g}(t) r_{p}^{2}\right) & \ddots & \\
& & & & & \ddots & \\
& & & & & \ddots & \\
& & & & & k_{n-3}+k_{n-2} & -k_{n-2} \\
& & & & & -k_{n-2} & k_{n-1}
\end{array}\right] \text {, }
$$

where $k_{i}$ is the torsional stiffness of axial element, and $K_{g}(t)$ is the time-varying meshing stiffness.

$Q$ is the excitation matrix:

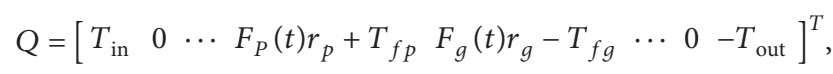

where $F_{p}(t)$ and $F_{g}(t)$ are, respectively, the dynamic meshing forces of the pinion and gear, $T_{\text {in }}$ and $T_{\text {out }}$ are, respectively, the input and load torque, and $T_{f p}$ and $T_{f g}$ are the time-varying friction moments of the main and driven gears, respectively.

2.2. Mathematical Model of Time-Varying Meshing Stiffness. The contact ratio of gear is not an integer, and the number of the tooth involved in the mesh process changes periodically with time, so the meshing stiffness of the gear teeth also changes periodically with time, and the stiffness excitation makes the dynamic equation of the geared transmission contain time-varying coefficient, which makes it a time-varying nonlinear system. The general expression of time-varying mesh stiffness of single-teeth is shown in

$$
k_{n}=\frac{F_{n}(t)}{u_{n}(t)}
$$

where $F_{n}(t)$ is the normal dynamic meshing force acting on the tooth profile surface, and $u_{n}(t)$ is the comprehensive elastic deformation of single pair gear tooth, which includes contact elastic deformation $\left(u_{h}\right)$ and the displacement of 
tooth contact caused by tooth bending $\left(u_{b}\right)$, so $u_{n}(t)$ can get by

$$
u_{n}=\sum_{i=1}^{2} u_{h i}+\sum_{i=1}^{2} u_{b i}
$$

When multitooth meshing occurs, the multipair tooth are coupled in parallel. Therefore, the time-varying mesh stiffness of the gears can be expressed as follows:

$$
k_{m}=\sum_{i=1}^{p} k_{n i}
$$

where $p$ is the number of gear pair in contact process.

\subsection{Mathematical Model of Time-Varying Friction Torque of} Spiral Bevel Gears. At present, the contact analysis theory of spiral bevel gears is not mature. To simplify the calculation, the spiral bevel gears are equivalent to helical gears in this study. The friction moment calculation model in literature [15] was adopted, which defined that gear has multiple contact lines. When the contact line is located outside the pitch circle, the friction force is positive, while the friction force inside the pitch circle is negative, and its direction is perpendicular to the contact line. In this study, the form of broken tooth perpendicular to the direction of tooth width is studied. Assuming that the contact line is uniformly distributed in the direction of tooth width, the contact area of broken tooth is shown in Figure 2, where $P_{t}, P_{n}$, and $\alpha_{b}$ are the transverse pitch, normal pitch, and base helix angle, respectively. $L^{\prime}$ is the length of the broken tooth along the width of equivalent gear, and $L_{1}, L_{2}, L_{3}$ are the lengths of contact line at different states. Equation (10) is a friction calculation formula based on the dynamic engagement line. The friction on the $i^{\text {th }}$ contact line is as follows:

$$
F_{f i}=-\mu \frac{F}{L} \Delta L_{i}, \quad i=1, \ldots, n,
$$

where $F$ is the normal force acting on the tooth surface $(N), L$ is the total length of the contact lines(mm), $\Delta L_{i}$ is the difference between the length of two segments cutoff by the nodal circle of the contact line $(\mathrm{mm})$, and $\mu$ is the coefficient of friction. Then, the total friction is calculated:

$$
F_{f}=\sum_{i=1}^{n} F_{f i}, \quad i=1, \ldots, n .
$$

The sign convention of the frictional torque is considered as positive when it facilitates the rotation and negative otherwise. The formula for calculating the friction torque on the contact line of the $i^{\text {th }}$ line is as follows:

$$
T_{f i}=\sum_{i}^{n} \mu F_{f i} \Delta l_{i}, \quad i=1, \ldots, n,
$$

where $\Delta l_{i}$ is the friction arm on the $i^{\text {th }}$ contact line.

\section{Analysis of Torsional Vibration Characteristics of the Spiral Bevel Geared Transmission System with Broken Tooth}

3.1. Finite Element Model of Spiral Bevel Gear Pair. Spiral bevel gears pair is compact in structure, stable in transmission, and able to change the direction of power transmission. In this study, a spiral bevel geared transmission is taken as an example to study the dynamic response of the transmission with time-varying excitation. Its structure is shown in Figure 3, and its structural parameters are shown in Table 1.

3D modelling software (UG) was used to establish the solid model of spiral bevel gear pair with broken teeth, which was imported into ANSYS for analysis. Contact area of tooth pair use CONTA174 unit and TARGET170 unit, the solid model adopt the SOLID186 unit, the broken area use the tetrahedrons dividing method, and the normal region use the hex-dominant division method. In order to save computing resources, spiral bevel gears were cut and 5 pairs of gear tooth were reserved for dynamic meshing analysis. The meshing simulation model of spiral bevel gears is shown in Figure 4 . The ratio of the arc length of the gear tooth to the length of the broken tooth represents the different degrees of the broken tooth failure, namely, $L / S \times 100 \%=\{20 \%, 30 \%, 40 \%, 50 \%, 60 \%\}$, and the geometric model of broken teeth is shown in Figure 5.

\subsection{Time-Varying Excitation Analysis of Spiral Bevel Gears with Broken Tooth}

3.2.1. Time-Varying Mesh Stiffness Analysis. The broken tooth failure will lead to reduction of time-varying meshing stiffness. The more serious the broken tooth failure is, the more meshing stiffness of a single-teeth decreases, as shown in Figure 6(a). Time-varying meshing stiffness of multiple teeth is calculated according to the contact ratio and the loading contact analysis, as shown in Figure 6(b).

3.2.2. Time-Varying Friction Moment Analysis. The timevarying friction torque under broken tooth failure is shown in Figure 7. It can be seen from Figure 7 that the value of the friction torque has a sudden change at the pitch circle. This is because the direction of the tooth surface friction will change to the opposite direction after crossing the pitch circle, which conforms to the existing gear meshing principle. At the same time, as the degree of broken tooth increases, the value of time-varying friction torque decreases to varying degrees. Because spiral bevel gears belong to multitooth meshing, a single-tooth breaks down and causes a limited reduction in friction torque.

3.3. Torsional Vibration Characteristics Analysis of the Transmission System with Broken Tooth. Angular displacement calculation is the basic content of torsional vibration research. In this study, the numerical method is used to solve equation (1). This numerical method does 


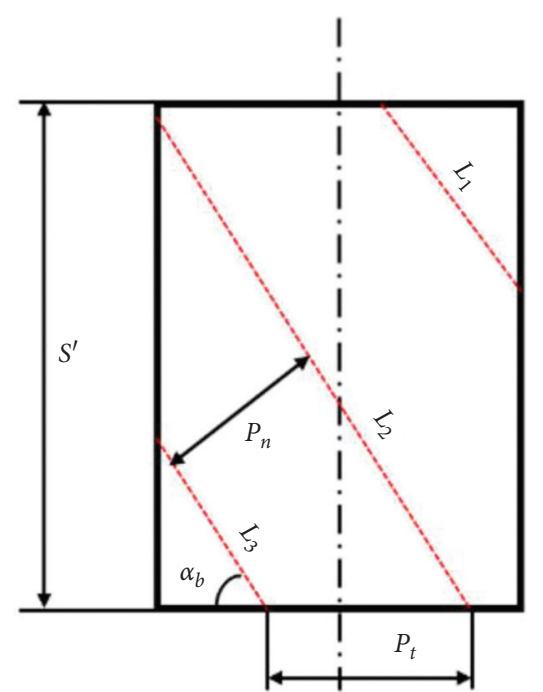

(a)

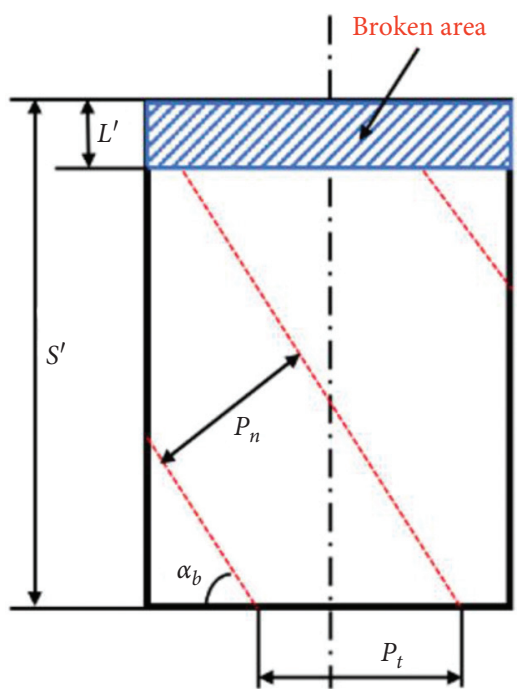

(b)

FIgURE 2: Diagram of meshing contact area of broken teeth.

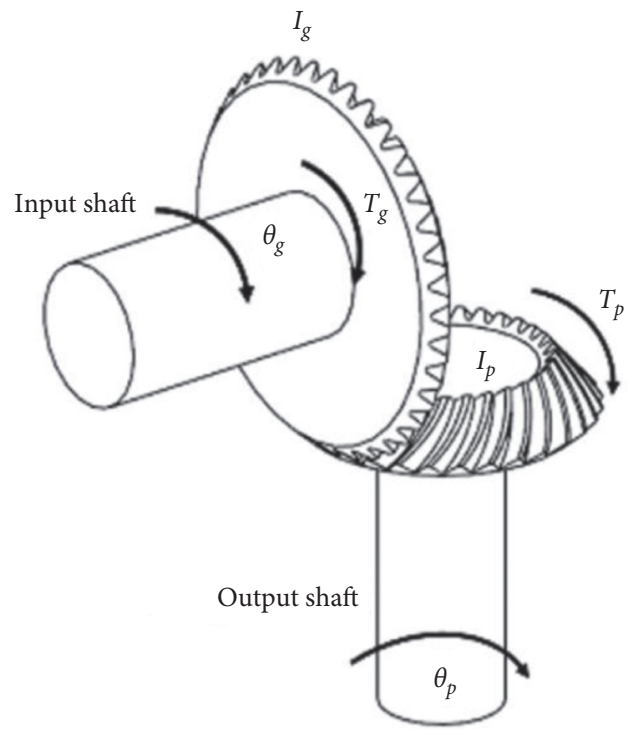

FIGURE 3: Diagram of spiral bevel gear pair.

TABLE 1: Design parameters of gears.

\begin{tabular}{lcc}
\hline Parameter & Pinion & Gear \\
\hline Modulus & 7.98 & 7.98 \\
Number of teeth & 14 & 41 \\
Pressure angle $\left(^{\circ}\right)$ & 20 & 20 \\
Helix angle $\left(^{\circ}\right)$ & 35 & 35 \\
Angle of shafts $\left(^{\circ}\right)$ & 90 & 90 \\
Base width $(\mathrm{mm})$ & 55 & 55 \\
Mass $(\mathrm{kg})$ & 1.51 & 12.955 \\
Moment of inertia $\left(\mathrm{kg} * \mathrm{~m}^{2}\right)$ & $9.25 \times 10^{-4}$ & $6.8 \times 10^{-2}$ \\
\hline
\end{tabular}

not need to distinguish whether the system contains proportional damping and has good stability. Generally, when $\theta>1.37$, the algorithm can be guaranteed to be

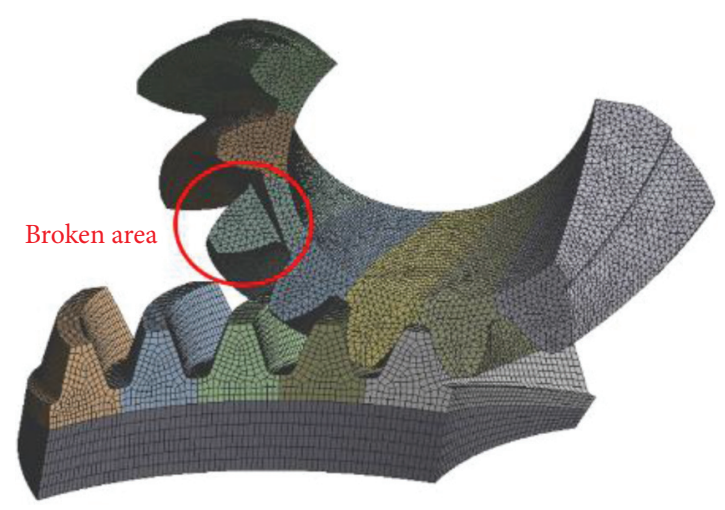

FIgURE 4: Meshing simulation model of spiral bevel gear.

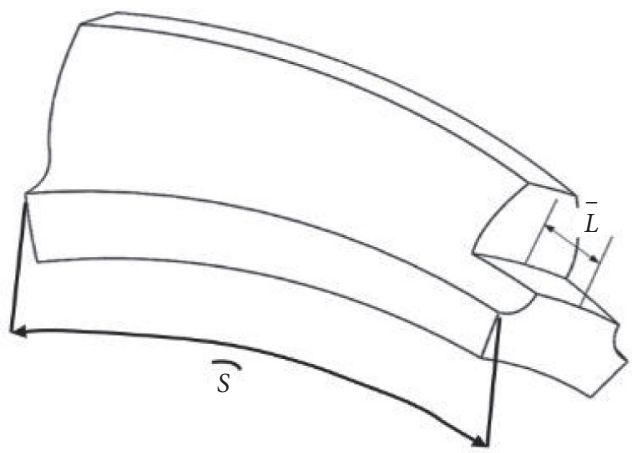

FIGURE 5: Geometric model of broken teeth.

unconditionally stable. In this study, $\theta=1.4$, and the input speed is $1000 \mathrm{r} / \mathrm{min}$.

3.3.1. Time-Domain Response Characteristics of the Transmission System. Torsional vibration essentially reflects the relative value of angular displacement between two points 


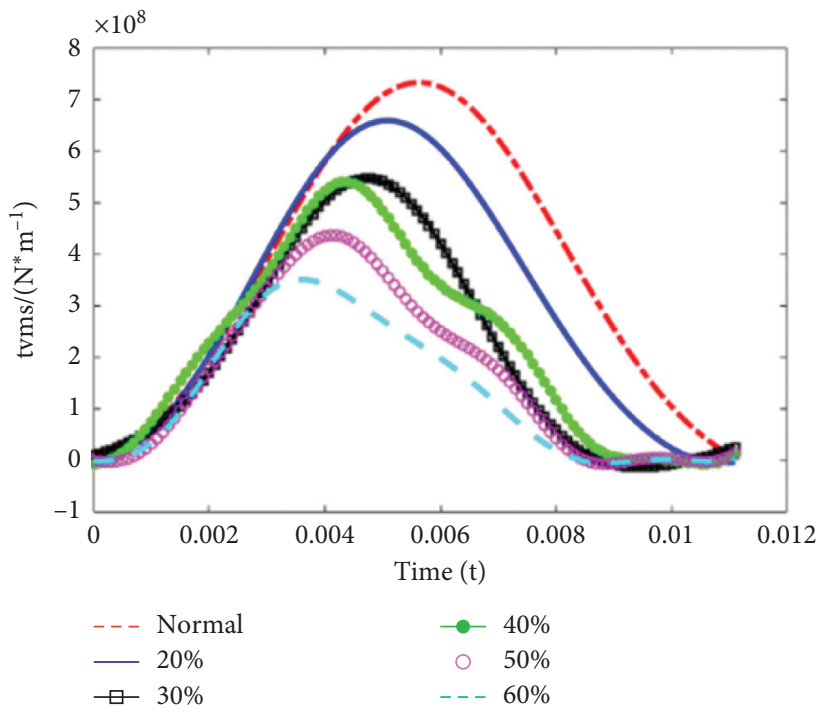

(a)

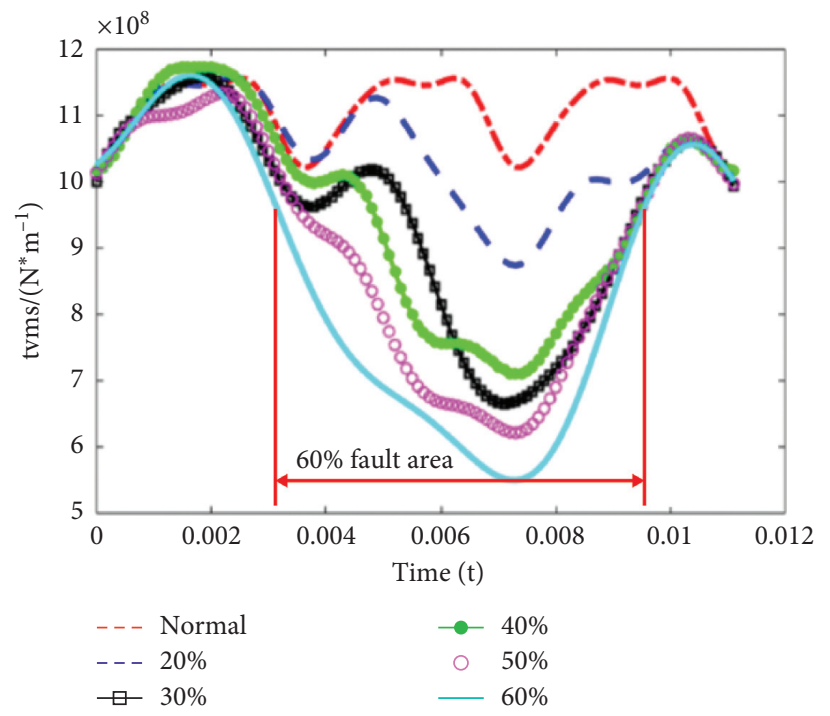

(b)

FIGURE 6: Time-varying meshing stiffness of spiral bevel gears with broken teeth: (a) tvms of single-teeth and (b) tvms of multitooth.

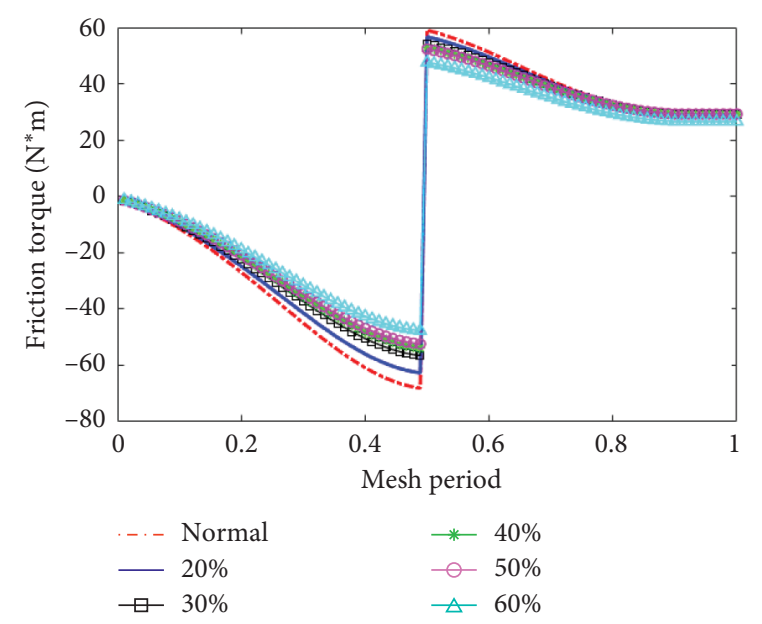

FIgURE 7: Time-varying friction torque with broken tooth.

along the axis, so formula (13) is used to measure torsional vibration of the spiral bevel geared transmission system.

$$
x_{t}=\left(R_{b 2} \theta_{2}-R_{b 1} \theta_{1}\right) \text {, }
$$

where $\theta_{1}, \theta_{2}$ represent the angular displacements at the pinion and gear, respectively. $R_{b 1}, R_{b 2}$ represent the base circle radius of pinion and gear, respectively.

It can be seen from Figure 8, when the spiral bevel gear has broken tooth failure, the torsional vibration response of the system has obvious periodic impact vibration. After the friction force is included in the model, the vibration amplitude increases to some extent, and the more serious the broken tooth failure is, the more the vibration amplitude increases.

For further analysis, the influence of different degrees of broken tooth failure on torsional vibration, three statistical indexes, such as root mean square error (RMS), kurtosis, and crest factor is used to analyse the time-domain response. The statistics index of time-domain response of torsional vibration with various degrees of broken teeth failures is shown in Figure 9. The crest factor increases significantly before the broken tooth failure reaches $30 \%$, that is, the crest factor is more sensitive to the minor broken tooth failure, while during $30-60 \%$ of the broken tooth failure, the change is tiny, that is, the crest factor is not sensitive to the serious broken tooth failure. Before the tooth failure reaches $30 \%$, kurtosis has a small change, $30-40 \%$ has an increase, and $40-60 \%$ has an obvious increase. Kurtosis is not sensitive to minor tooth failure, but extremely sensitive to severe tooth failure.

3.3.2. Frequency-Domain Response Characteristics of the Transmission System. As the increase of degrees of broken tooth failures, the response characteristics of torsional vibration of the system in frequency domain are shown in Figure 10. It can be clearly seen from Figure 10 that there is obvious meshing frequency $\left(f_{e}=233 \mathrm{~Hz}\right)$ and its harmonic frequency. After the gear tooth failure occurs, the rotation frequency $\left(f_{r}=16.6 \mathrm{~Hz}\right)$ and the side frequency band of mesh frequency appear in the spectrum diagram. With the aggravation of failure degree, the side bands of meshing frequency have enriched, especially the low-frequency bands before the first-order meshing frequency. As the single-tooth failure is studied in this study, the firstorder rotation frequency $(16.6 \mathrm{~Hz})$ is distinct, and the multifold rotation frequency appears in the spectrum diagram.

\section{Experimental Verification}

4.1. Vibration Test of the Spiral Bevel Geared Transmission System with Broken Teeth. In order to verify the correctness of the simulation results, the vibration experiment of the 


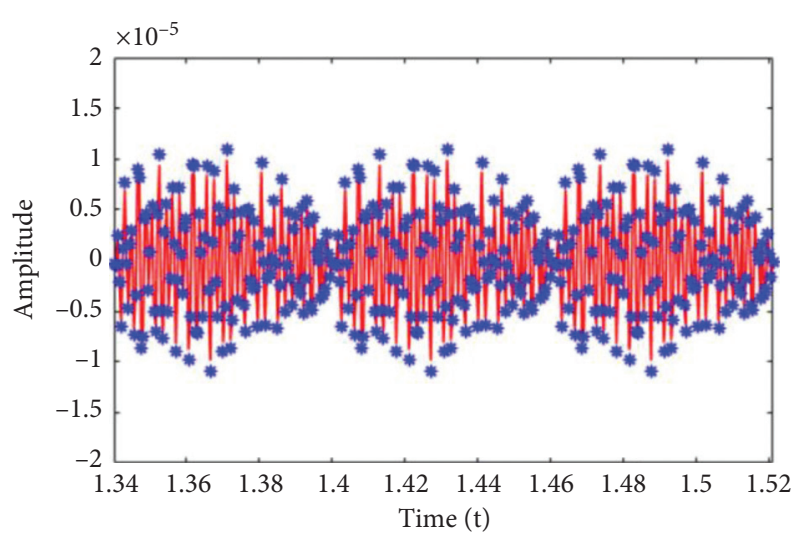

- No friction

* With friction

(a)

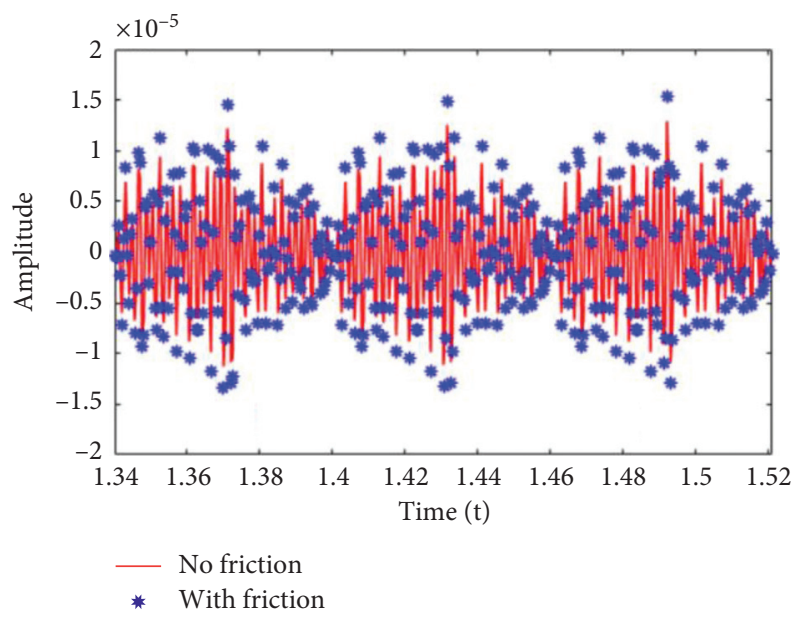

(c)

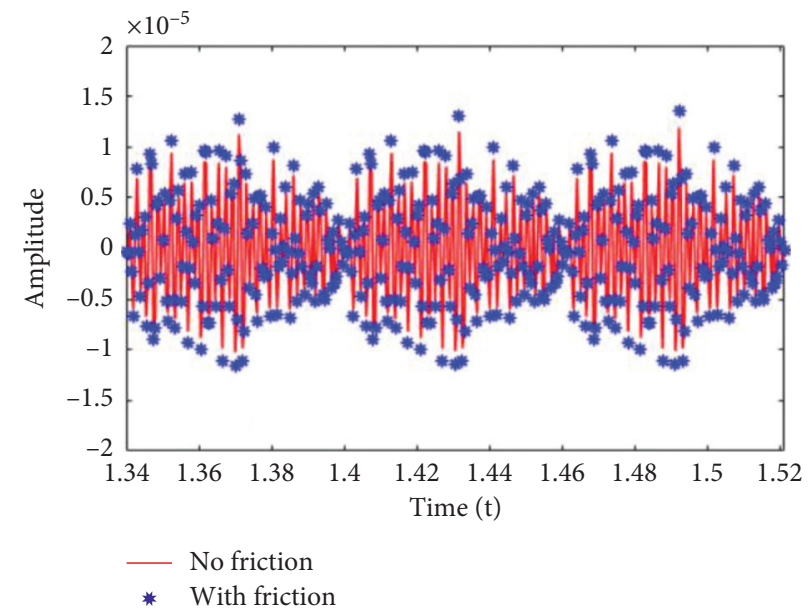

(b)

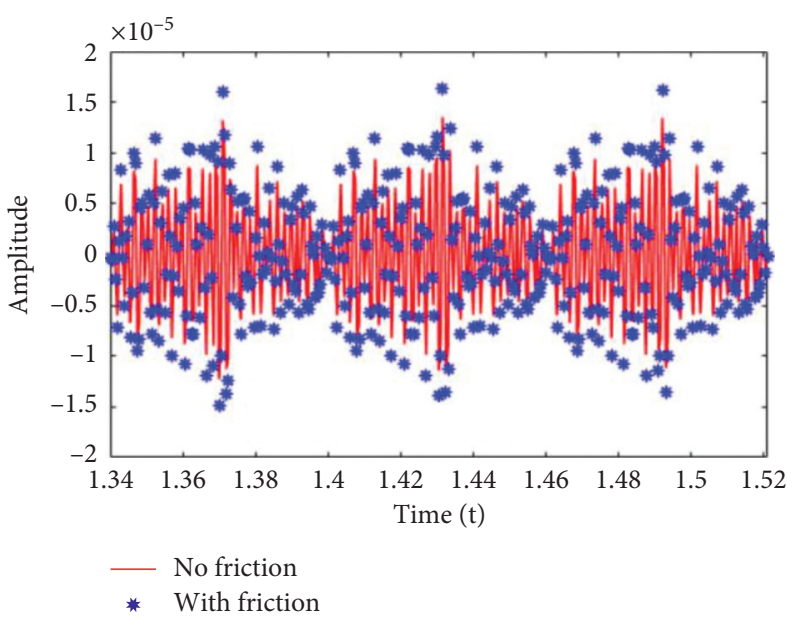

(d)

Figure 8: Time-domain response of torsional vibration of the transmission system. (a) Normal teeth. (b) $20 \%$. (c) $30 \%$. (d) $40 \%$.

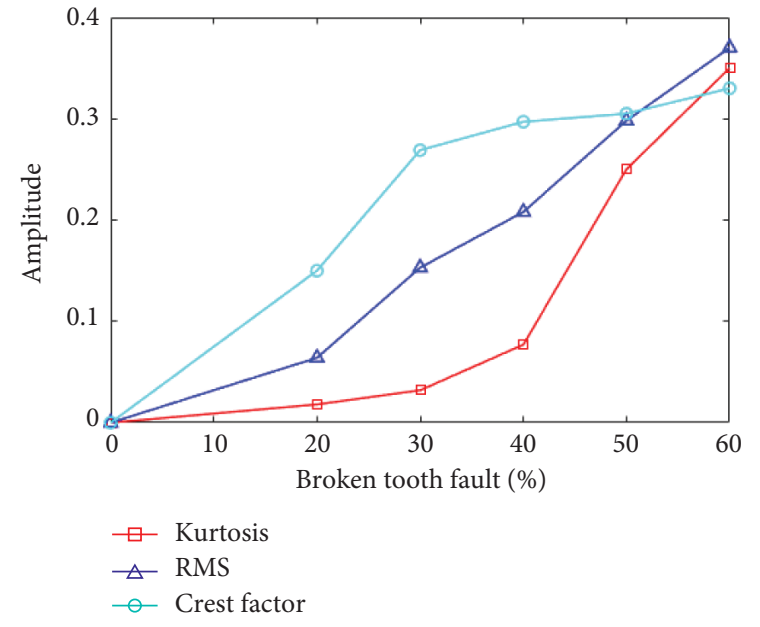

Figure 9: Time-domain statistical index.

spiral bevel geared transmission system with broken tooth failure was carried out. The spiral bevel gearbox used for the vibration test is shown in Figure 11. The test equipment is composed of a governor, a motor, couplings, a pair of spiral bevel gears, and a load. The driving gear is used as the test gear to simulate three typical failure gears, namely, normal tooth, $1 / 3$ broken tooth, and $2 / 3$ broken tooth. Vibration signals were collected using B\&K's PULSE data acquisition system. During the test, the speed of the motor was kept constant at $1000 \mathrm{r} / \mathrm{min}$ by adjusting the governor, and the sampling frequency was $6.4 \mathrm{kHz}$.

4.2. Frequency Domain Response Analysis of Experimental Result. As can be seen from Figure 12, when there are different degrees of broken teeth faults, the system response has obvious meshing frequency. When the system is a normal gear, the amplitude of low-frequency band is small, and the rotating frequency and its component is not obvious, as shown in Figure 12(a). When the system has a broken tooth failure $(30 \%)$, the amplitude of the rotating frequency component caused by the broken tooth failure increases significantly, which also has an obvious $f_{r}$, as shown in Figure 12(b). 


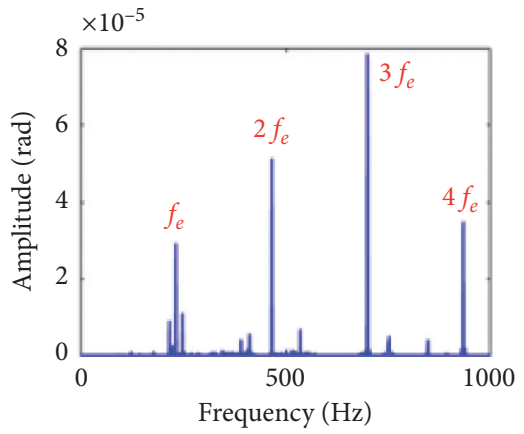

(a)

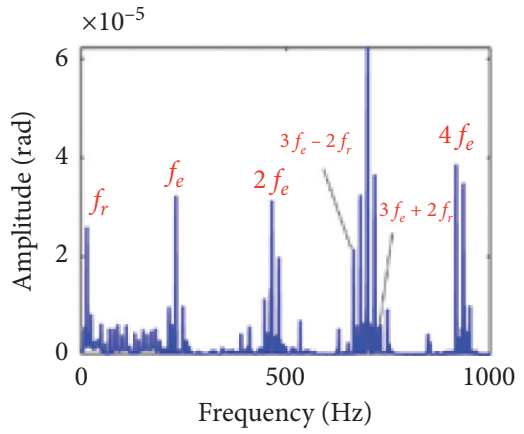

(d)

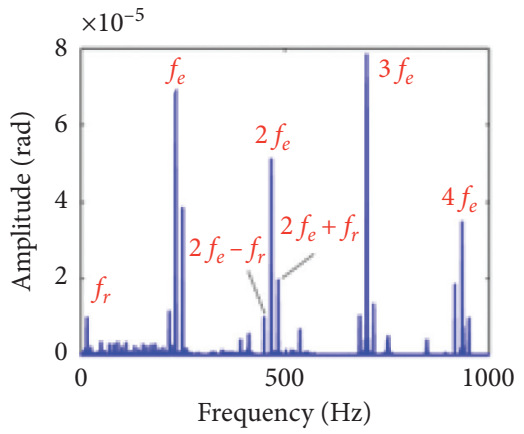

(b)

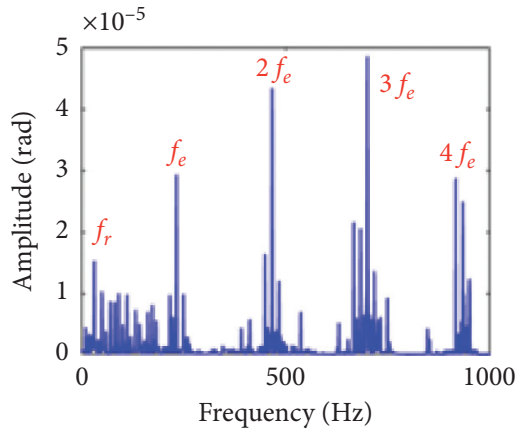

(e)

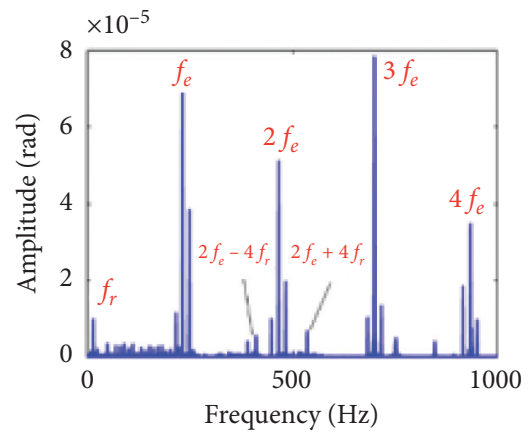

(c)

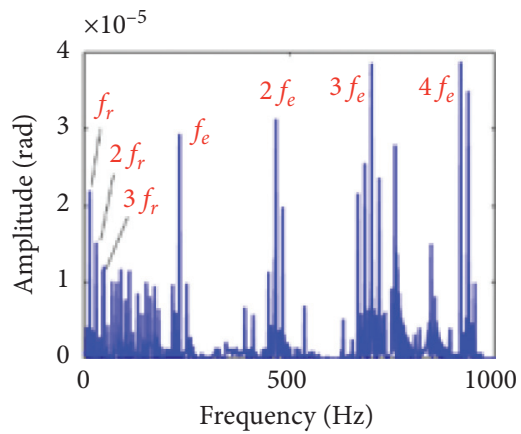

(f)

Figure 10: The spectrum diagram of the broken tooth failure. (a) Normal teeth. (b) $20 \%$. (c) $30 \%$. (d) $40 \%$. (e) $50 \%$. (f) $60 \%$.

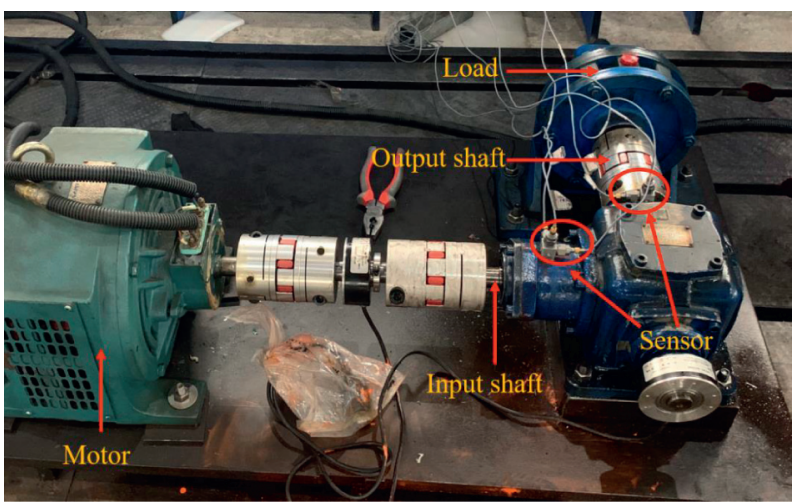

FIGURE 11: Spiral bevel gearbox test equipment.

4.3. Analysis of the Influence of Time-Varying Friction Excitation on Low-Frequency Band. It can be seen from Figures 10 and 12 that the more serious the broken tooth failure is, the more abundant the low-frequency band is, and the more energy it contains. Therefore, the energy of low-frequency band can be used to further study the influence of time-varying friction excitation on the dynamic response of the geared transmission system. The energy ratio is defined to represent the contribution of time-varying frictional excitation to low-frequency band energy, as shown in

$$
\eta_{l f b}=E_{f b}-E_{b} / E_{f b} \times 100 \%
$$

where $E_{f b}$ is the sum value of energy of the low-frequency band with the frictional excitation, and $E_{b}$ is the sum value of energy of low-frequency band without frictional excitation.

The variation of the contribution of experiment and simulation with different failure degrees of broken tooth is shown in Figure 13. It can be seen from Figure 13 that the contribution of friction excitation to low-frequency band is $12 \%$ with no broken tooth failure. After broken tooth failure occurs, the friction excitation decreases, resulting in the decrease of the contribution to low-frequency band as the increase of failure degrees. The variation trend of the experiment and the simulation results are basically consistent, but the time-varying frictional excitation in the experiment 


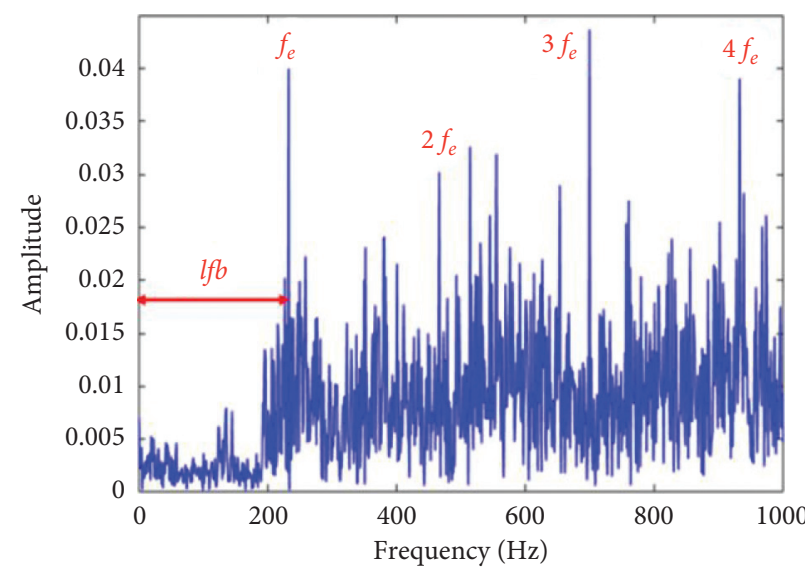

(a)

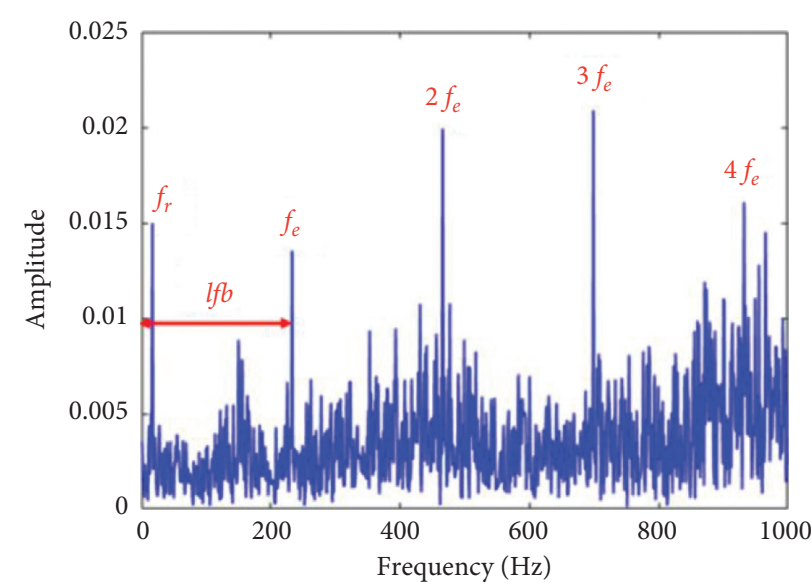

(b)

Figure 12: Test frequency domain response diagram of broken tooth failure.

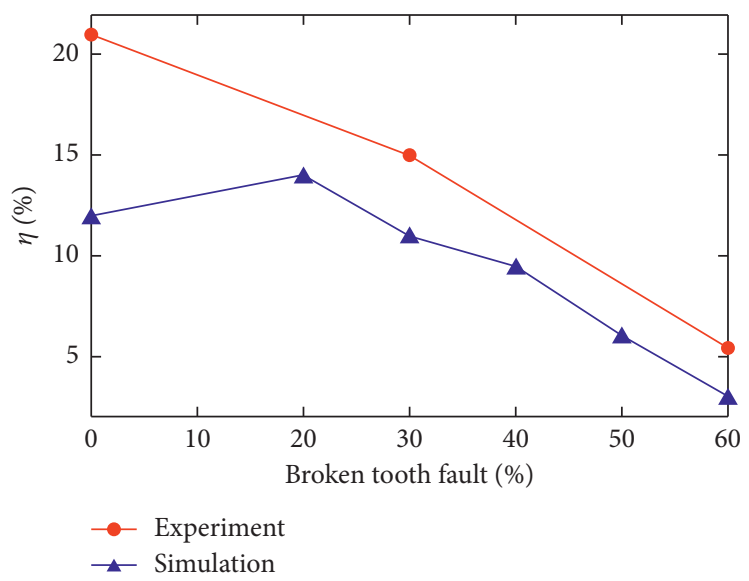

FIGURE 13: Influence of time-varying friction excitation on low-frequency band.

has a greater contribution to the low-frequency band than the simulation results. The contribution is about $21 \%$ and $6 \%$ with normal tooth and $60 \%$ broken teeth failures, respectively. The difference may be caused by unbalanced excitation and mesh error excitation generated by tooth failures, both of which can provide energy for the low-frequency band.

\section{Conclusion}

In this study, the torsional vibration characteristics of the spiral bevel geared transmission system with various degrees of broken tooth failures are studied by considering the timevarying excitation. The following conclusions are drawn:

(1) The sensitivity of three time-domain statistical indexes, RMS, kurtosis, and crest factor to broken teeth failures were compared. It was found that the crest factor was sensitive to minor broken teeth failures $(10 \%-30 \%)$, while kurtosis is sensitive to severe failure $(30 \%-60 \%)$;

(2) As the degrees of broken tooth failures increase, the energy of low-frequency band increases obviously. Frictional excitation of normal teeth contributes approximately $12 \%-21 \%$ of the energy to the lowfrequency band by a further study on the low-frequency band. And with the increase of the failure degrees, the value decreases from $17 \%$ to $5 \%$.

\section{Data Availability}

The data used to support the findings of this study are available from the corresponding author or the second author upon request. 


\section{Conflicts of Interest}

The authors declare that they have no conflicts of interest.

\section{Acknowledgments}

This study was supported by the National Natural Science Foundation of China (Grant nos. 11872022 and 11702091) and the Natural Science Foundation of Hunan Province of China (Grant nos. 2019JJ50156 and 2018JJ3140).

\section{References}

[1] A. Saxena, A. Parey, and M. Chouksey, "Time varying mesh stiffness calculation of spur gear pair considering sliding friction and spalling defects," Engineering Failure Analysis, vol. 70, pp. 200-211, 2016.

[2] H. Ma, Z. Li, M. Feng, R. Feng, and B. Wen, "Time-varying mesh stiffness calculation of spur gears with spalling defect," Engineering Failure Analysis, vol. 66, pp. 166-176, 2016.

[3] X. H. Liang, H. S. Zhang, L. B. Liu et al., "The influence of tooth pitting on the mesh stiffness of a pair of external spur gears," Mechanism and Machine Theory, vol. 106, pp. 1-15, 2016.

[4] R. Shao, P. Jia, and F. Dong, "Dynamic characteristics of cracked gear and three-dimensional crack propagation analysis," Proceedings of the Institution of Mechanical Engineers, Part C: Journal of Mechanical Engineering Science, vol. 227, no. 6, pp. 1341-1361, 2013.

[5] O. D. Mohammed, M. Rantatalo, J.-O. Aidanpää, and U. Kumar, "Vibration signal analysis for gear fault diagnosis with various crack progression scenarios," Mechanical Systems and Signal Processing, vol. 41, no. 1, pp. 176-195, 2013.

[6] S. A. Mohamed, T. Moez, C. Fakher, F. Tahar, and H. Mohamed, "Dynamic behaviour modeling of a flexible gear system by the elastic foundation theory in presence of defects," European Journal of Mechanics, vol. 29, pp. 887-896, 2010.

[7] Z. Chen and Y. Shao, "Mesh stiffness calculation of a spur gear pair with tooth profile modification and tooth root crack," Mechanism and Machine Theory, vol. 62, pp. 63-74, 2013.

[8] H. Ma, X. Pang, Q. Wang, R. Song, and B. Wen, "Commentary on effects of tip relief on vibration responses of a geared rotor system," Proceedings of the Institution of Mechanical Engineers, Part C: Journal of Mechanical Engineering Science, vol. 231, no. 11, pp. 2159-2169, 2017.

[9] H. Chen, Y. Shang, and K. Sun, "Multiple fault condition recognition of gearbox with sequential hypothesis test," Mechanical Systems and Signal Processing, vol. 40, no. 2, pp. 469-482, 2013.

[10] R. L. Li and J. J. Wang, Dynamics of Gear System: Vibration, Impact and Noise, Science Press, Beijing, China, 1997.

[11] H. Ma, J. Zeng, R. Feng, X. Pang, Q. Wang, and B. Wen, "Review on dynamics of cracked gear systems," Engineering Failure Analysis, vol. 55, pp. 224-245, 2015.

[12] H. Ma, R. Song, X. Pang, and B. Wen, "Time-varying mesh stiffness calculation of cracked spur gears," Engineering Failure Analysis, vol. 44, pp. 179-194, 2014.

[13] Z. Chen, W. Zhai, Y. Shao, K. Wang, and G. Sun, "Analytical model for mesh stiffness calculation of spur gear pair with non-uniformly distributed tooth root crack," Engineering Failure Analysis, vol. 66, pp. 502-514, 2016.
[14] Q. Wang, "A mesh stiffness method using slice coupling for spur gear pairs with misalignment and lead crown relief," Applied Mathematical Modelling, vol. 90, pp. 845-861, 2011.

[15] Q. Wang, B. Zhao, Y. Fu, X. Kong, and H. Ma, "An improved time-varying mesh stiffness model for helical gear pairs considering axial mesh force component," Mechanical Systems and Signal Processing, vol. 106, pp. 413-429, 2018.

[16] J. Tang and T. P. Pu, "Spiral bevel gear meshing stiffness calculations based on the finite element method," Journal of Mechanical Engineering, vol. 47, no. 11, pp. 23-29, 2011.

[17] H. Xu, "Development of a generalized mechanical efficiency prediction methodology for gear pairs," Electronic Thesis or Dissertation, Ohio State University, Columbus, OH, USA, 2005.

[18] O. Lundvall, N. Strömberg, and A. Klarbring, "A flexible multi-body approach for frictional contact in spur gears," Journal of Sound and Vibration, vol. 278, no. 3, pp. 479-499, 2004.

[19] C. Kar and A. R. Mohanty, "An algorithm for determination of time-varying frictional force and torque in a helical gear system," Mechanism and Machine Theory, vol. 42, no. 4, pp. 482-496, 2007.

[20] L. Han and H. Qi, "Dynamics responses analysis in frequency domain of helical gear pair under multi-fault conditions," Journal of Mechanical Science and Technology, vol. 33, no. 11, pp. 5117-5127, 2019.

[21] L. Xiang and N. Gao, "Coupled torsion-bending dynamic analysis of gear-rotor-bearing system with eccentricity fluctuation," Applied Mathematical Modelling, vol. 50, pp. 569584, 2017.

[22] X. Y. Yang, X. J. Zhou, and H. W. Hu, "Nonlinear vibration characteristics and parameter influence of spiral bevel gears," Journal of Zhejiang University: Engineering Science, vol. 43, no. 3, pp. 505-510, 2009.

[23] Q. Wang, Z. Li, H. Ma, and B. Wen, "Effects of different coupling models of a helical gear system on vibration characteristics," Journal of Mechanical Science and Technology, vol. 31, no. 5, pp. 2143-2154, 2017.

[24] F. Z. Geng, L. J. Yang, and Y. F. Li, "Realization of doublebranch split-torque transmission system of gearbox and analysis of its rotor dynamic," Journal of Mechanical Transmission, vol. 44, no. 6, pp. 84-88, 2020.

[25] H. Zhang, H. Feng, and L. J. Ding, "Gear fault identification based on torsional vibration analysis method," Acta Metrologica Sinica, vol. 40, no. 2, pp. 300-305, 2019.

[26] Y. Yang, W. Xia, J. Han, Y. Song, J. Wang, and Y. Dai, "Vibration analysis for tooth crack detection in a spur gear system with clearance nonlinearity," International Journal of Mechanical Sciences, vol. 157, pp. 648-661, 2019.

[27] O. Doğan and F. Karpat, "Crack detection for spur gears with asymmetric teeth based on the dynamic transmission error," Mechanism and Machine Theory, vol. 133, pp. 417-431, 2019. 